\title{
Metastable Transitions in Mass Spectra of Hydrocarbons
}

\author{
By Evelyn G. Bloom, Fred L. Mohler, C. Edward Wise, and Edmund J. Wells
}

This paper gives a compilation of metastable transition peaks in mass spectra of about 170 hydrocarbons based on experimental data that have been published in the American Petroleum Institute Catalog of Mass Spectra Data. One hundred different transitions have been found and identified. These are tabulated according to the mass lost in the transition. Masses lost are 1, 2, 15, 16, 26, 27, 28, 29, 30, 40,42, 43, 44, 56, 57, and 58. Nearly all transitions can be ascribed to breaking of one bond with or without the transfer of one hydrogen atom to the charged or to the neutral fragment. The data include those previously reported in Research Paper 1888 [1]. ${ }^{1}$

\section{Introduction}

A previous paper has discussed the metastable transitions in mass spectra of 56 hydrocarbons [1]. The experimental data published by this laboratory in the American Petroleum Institute Catalog of Mass Spectral Data [2] now include nearly 170 hydrocarbons. All observable metastable transition peaks have been indicated in the tables, and the transitions giving rise to the peaks have been unambiguously identified in nearly all cases. This paper is a brief summary of the transitions observed to date, including and greatly extending the lists in the previous paper [1].

Metastable transition peaks are observed as small abnormally wide peaks that are in general at nonintegral mass positions. Hipple and Condon [3] bave shown that these peaks arise from ions that dissociate after the ions have passed through the ion accelerating field. For this reason they have less than the full kinetic energy and an apparent mass, $m_{a}$, which is less than the true mass and given by the relation

$$
m_{a}=m_{f}^{2} / m_{i}
$$

where $m_{i}$ is the mass during passage through the electric field, and $m_{f}$ is the mass after dissociation.

\footnotetext{
${ }_{1}^{1}$ Figures in brackets indicate the literature references at the end of this paper.
}

$m_{i}$ may be either the mass of the parent ion or the mass of a dissociation product formed in the ionization chamber before entering the ion accelerating field.

Theoretically the measured value of $m_{a}$ is sufficient to determine both $m_{f}$ and $m_{i}$, since $\mathrm{m}_{f}$ and $m_{i}$ are integers. In practice a qualitative intensity rule is very helpful in the identification of the transition, namely that the height of the metastable peak depends on the intensity of both the peaks $m_{f}$ and $m_{i}$ and both will have an intensity of greater than 5 percent of the maximum peak if the metastable transition is observable. The experimental evidence for this rule has already been discussed [1].

The Socony Vacuum Laboratories and the Atlantic Refining Co. have published mass spectra of a number of the hydrocarbons included in the National Bureau of Standards study and have included metastable peaks [2]. There is usually good agreement between laboratories in spite of the fact that identification of these small peaks is sometimes a matter of personal judgment and experience.

The hydrocarbons covered in this study include 59 straight-chain saturated hydrocarbons, including $n$-decane, 18 nonanes and all lighter saturates; 34 olefins, including 1 -decene, 1-nonene, 4 octenes, 3 heptenes, 13 hexenes and all lighter olefins; 21 
alkylcyclopentanes, 17 alkylcyclohexanes, 20 alkylbenzenes, 5 dienes, 3 acetylenes, 6 cyclopropanes and cyclobutanes, and 3 cycloolefins.

\section{Experimental Results}

The following tables list 100 different metastable transitions that have been observed in hydrocarbon mass spectra. Many of these recur in many different hydrocarbons, and over a thousand different instances of metastable transitions are noted in the API tables. Here the transitions are classified according to the mass lost in the metastable transition. The first column of each table gives the apparent mass and is the value computed from the initial and final masses listed in columns 2 and 3 . In the last column is indicated the compounds, or class of compounds, showing the transition. When a transition occurs only in one or two compounds or one or two classes of compounds, these are indicated specifically. If it occurs in three or more compounds, only the class of compound is indicated, and if it occurs in three or more classes it is listed as common. The abbreviation $p$ is used for the parent ion. The information on occurrence of metastable transitions must be evaluated with due regard to the above list of compounds studied. Data on diolefins, acetylenes, and cycloolefins are very incomplete.

Loss of mass 1 (table 1). The loss of $\mathrm{H}$ in a metastable transition is very rare in view of the fact that in every spectrum there are many large peaks differing by one mass unit. In addition to the four transitions listed in table 1, the Socony Vacuum Laboratories [4] list two such transitions in propylene; $42^{+} \rightarrow 41^{+}+1$ and $40^{+} \rightarrow 39^{+}+1$. Although the transitions were not observed in our work, there is no reason to doubt these observations. These metastable transition peaks coincide with large normal peaks and it requires careful study of the peak shape to prove that they exist. The second of these transitions gives an apparent mass of 38.0. An alternative explanation would be $42^{+} \rightarrow 40^{+}+2$ with an apparent mass of 38.1 .

It is of interest that the transition $68^{+} \rightarrow 67^{+}$ occurs in nearly all the $\mathrm{C}_{5} \mathrm{H}_{8}$ isomers that have been studied, for these include a wide variety of compounds; spiropentane, cyclopentene, methylenecyclobutane, several pentadienes, and 1-pen- tyne. In all these spectra the loss of $\mathrm{H}$ from the parent ion is a very probable transition, often the maximum peak.

TaBle 1. Transitions involving loss of mass 1

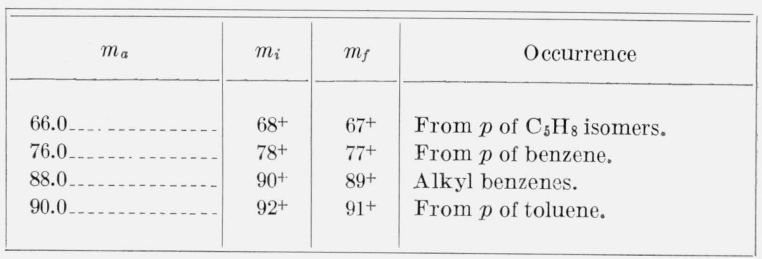

Loss of mass 2 (table 2). This is by far the most common type of metastable transition and is observed in most cases where there are two strong peaks differing by two mass units.

TABLE 2. Transitions involving loss of mass 2

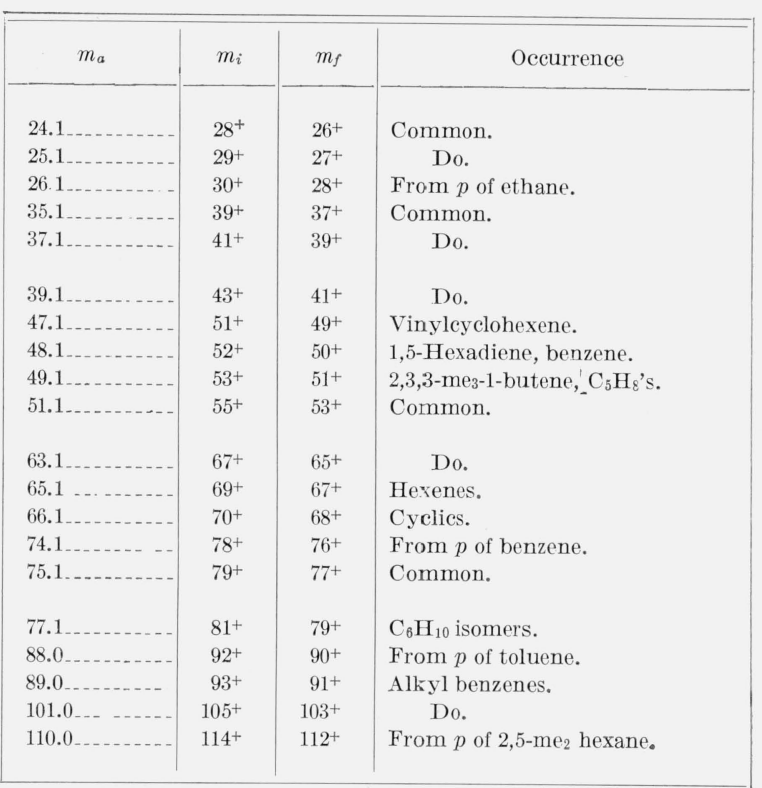

Loss of mass 15 (table 3). In the earlier work [1] all instances of loss of $\mathrm{CH}_{3}$ in a metastable transition involved the parent ion, but cyclics and the heavier olefins were not included. As these molecule ions can dissociate into ions of lighter olefins (or ions isomeric with the lighter olefins), it is not surprising that this dissociation is followed by a metastable transition characteristic of the lighter olefin. In all instances of loss of $\mathrm{CH}_{3}$, the initial state is a molecule ion or at least an isomer of a molecule ion. 
TABLE 3. Transitions involving loss of mass 15

\begin{tabular}{|c|c|c|c|}
\hline$m_{a}$ & $m_{i}$ & $m_{f}$ & Occurrence \\
\hline $28.2 \ldots \ldots$ & $54^{+}$ & $39^{+}$ & $\begin{array}{l}\text { From } p \text { of } \mathrm{C}_{4} \mathrm{H}_{6} \text { 's and from } \mathrm{C}_{6} \mathrm{H}_{10} \text { 's } \\
\text { and vinvlcyclohexene. }\end{array}$ \\
\hline $30.0 \ldots \ldots$ & $56^{+}$ & $41^{+}$ & Cyclies and olefins. \\
\hline $31.9 \ldots$ & $58^{+}$ & $43^{+}$ & From $p$ of $n$-butane. \\
\hline $43.2 \ldots \ldots$ & $70^{+}$ & $55^{+}$ & Cyclies and olefins. \\
\hline $54.7 \ldots$. & $82^{+}$ & $67^{+}$ & From $p$ of $\mathrm{C}_{6} \mathrm{H}_{10}$ 's. \\
\hline $56.7 \ldots$ & $84^{+}$ & $69^{+}$ & Cyclics and olefins. \\
\hline 58.6 & $86^{+}$ & $71^{+}$ & From $p$ of $2,3-\mathrm{me}_{2}$ butane. \\
\hline $70.3_{\ldots} \ldots$ & $98^{+}$ & $83^{+}$ & Cyclics and olefins. \\
\hline $72.3_{\ldots} \ldots$ & $100^{+}$ & $85^{+}$ & From $p$ of 2 -methylhexane. \\
\hline $78.1 \ldots$ & $106^{+}$ & $91^{+}$ & From $p$ of $\mathrm{C}_{8} \mathrm{H}_{10}$ alkyl benzenes. \\
\hline $84.0 \ldots$ & $112^{+}$ & $97^{+}$ & From $p$ of $\mathrm{C}_{8}$ cyclies and olefins. \\
\hline $86.0 \ldots$ & $114^{+}$ & $99^{+}$ & $\begin{array}{l}\text { From } p \text { of } 2 \text {-me heptane and } 2,5 \text { - } \mathrm{me}_{2-} \\
\text { hexane. }\end{array}$ \\
\hline $91.9 \ldots$ & $120^{+}$ & $105^{+}$ & From $p$ of $\mathrm{C}_{9} \mathrm{H}_{12}$ alkyl benzenes. \\
\hline $105.7 \ldots$ & $134^{+}$ & $119^{+}$ & From $p$ of $\mathrm{C}_{10} \mathrm{H}_{14}$ alkyl benzenes. \\
\hline
\end{tabular}

Loss of mass 16 (table 4). The first two transitions listed in the table recur in many compounds, but other instances of losing $\mathrm{CH}_{4}$ are obviously very rare and a specific property of a few molecules. The transition giving 82.3 is of interest because all eight of the $\mathrm{C}_{8} \mathrm{H}_{16}$ cyclohexanes have been studied, and this is a conspicuous peak in trans 1,3-dimethylcyclohexane and cis 1,4-dimethylcyclohexane and is missing in all the others including the cis 1,3 and trans 1,4 isomers. The cis and trans isomers give mass spectra that are quite similar in other respects. The designation trans 1,3-dimethylcyclohexane is the revised designation for the compound of boiling point $124.45^{\circ}$ $\mathrm{C}$ [5].

TABLE 4. Transitions involving loss of mass 16

\begin{tabular}{|c|c|c|c|}
\hline$m_{a}$ & $m_{i}$ & $m_{f}$ & Occurrence \\
\hline $27.7 \ldots$ & $55^{+}$ & $39^{+}$ & Pentenes and hexenes. \\
\hline $29.5 \ldots$ & $57^{+}$ & $41^{+}$ & Common. \\
\hline $30.4 \ldots$ & $58^{+}$ & $42^{+}$ & From $p$ of $n$-butane. \\
\hline $82.3 \ldots$ & $112^{+}$ & $96^{+}$ & $\begin{array}{l}\text { From } p \text { of trans } 1,3-\mathrm{me}_{2} \text { cyclohexane } \\
\text { and cis } 1,4-\mathrm{me}_{2} \text { cyclohexane. }\end{array}$ \\
\hline
\end{tabular}

Loss of mass 26 (table 5). The second of these transitions has been listed [1]. The occurrence of transitions involving loss of $\mathrm{C}_{2} \mathrm{H}_{2}$ from benzene and alkyl benzenes is probably a consequence of a structure containing a ring of $\mathrm{CH}$ radicals dissociating by breaking carbon bonds.
Table 5. Transitions involving loss of mass 26

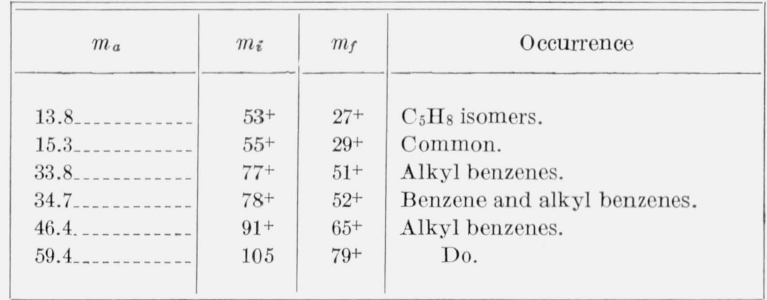

Loss of mass ${ }^{27}$ (table 6). The first transition was reported in the earlier paper [1]. The second transition occurs in dimethyl and ethyl benzenes. The fact that the final mass is $\mathrm{C}_{6} \mathrm{H}_{6}$ suggests that radicals are replaced by $\mathrm{H}$ atoms in a rearrangement of $\mathrm{H}$ atoms during the dissociation process.

TABLE 6. Transitions involving loss of mass 27

\begin{tabular}{|c|c|c|c|}
\hline$m_{a}$ & $m_{i}$ & $m_{f}$ & Occurrence \\
\hline $\begin{array}{l}13.5 \\
57.9\end{array}$ & $\begin{array}{r}54^{+} \\
105^{+}\end{array}$ & $\begin{array}{l}27^{+} \\
78^{+}\end{array}$ & $\begin{array}{l}\text { From } p \text { of } \mathrm{C}_{4} \mathrm{H}_{6} \text { isomers. } \\
\mathrm{C}_{8} \mathrm{H}_{40} \text { benzenes. }\end{array}$ \\
\hline
\end{tabular}

Loss of mass 28 (table 7 ). Loss of $\mathrm{C}_{2} \mathrm{H}_{4}$ is a common metastable transition reflecting the common occurrence of $\mathrm{CH}_{2} . \mathrm{CH}_{2}$ in molecular structure.

TABLE 7. Transitions involving loss of mass 28

\begin{tabular}{|c|c|c|c|}
\hline$m_{a}$ & $m_{i}$ & $m_{f}$ & Occurrence \\
\hline 24.4 & $69^{+}$ & $41^{+}$ & Olefins and cyclics. \\
\hline 25.2 & $70^{+}$ & $42^{+}$ & $\begin{array}{l}\text { From } p \text { of cyclopentane and from } \\
\text { other cyclies. }\end{array}$ \\
\hline $26.0 \ldots$ & $71^{+}$ & $43^{+}$ & From straight-chain saturates. \\
\hline $36.4 \ldots$ & $83^{+}$ & $55^{+}$ & Olefins and eyclies. \\
\hline $37.3 \ldots$ & $84^{+}$ & $56^{+}$ & $\begin{array}{l}\text { From } p \text { of } \mathrm{C}_{6} \text { cyclics and a few other } \\
\text { molecules. }\end{array}$ \\
\hline 38.2 & $85^{+}$ & $57^{+}$ & From straight-chain saturates. \\
\hline 43.6 & $91^{+}$ & $63^{+}$ & Toluene. \\
\hline $49.1 \ldots$ & $97^{+}$ & $69^{+}$ & Octenes and 1-nonene. \\
\hline 50.0 & $98^{+}$ & $70^{+}$ & Olefins and cyclies. \\
\hline $56.5 \ldots$ & $105^{+}$ & $77^{+}$ & Alkyl benzenes. \\
\hline $59.3 \ldots$ & $108^{+}$ & $80^{+}$ & From $p$ of vinylcyclohexene. \\
\hline $63.0_{---}$ & $112^{+}$ & $84^{+}$ & $\begin{array}{l}\text { From } p \text { of } \mathrm{C}_{8} \text { cyclies and from olefins } \\
\text { and } 1 \text {-decene. }\end{array}$ \\
\hline 69.6 & $119^{+}$ & $91^{+}$ & Alkyl benzenes. \\
\hline $76.2 \ldots$ & $126^{+}$ & $98^{+}$ & From $p$ of butyl cyclopentanes. \\
\hline $89.6--$ & $140^{+}$ & $112^{+}$ & From $p$ of 1-decene. \\
\hline
\end{tabular}

Loss of mass 29 (iable 8). Loss of the ethyl radical, $\mathrm{C}_{2} \mathrm{H}_{5}$, always comes from a parent ion, and in nearly all cases it could come from simple 
breaking of a carbon bond. Vinylcyclohexene does not contain a $\mathrm{CH}_{3}$ radical in its structure, and a rearrangement or double dissociation must be involved.

TABLE 8. Transitions involving loss of mass 29

\begin{tabular}{|c|c|c|c|}
\hline$m_{a}$ & $m_{i}$ & $m_{f}$ & Occurrence \\
\hline $24.0 \ldots \ldots$ & $70^{+}$ & $41^{+}$ & From $p$ of pentenes. \\
\hline $48.6 \ldots$ & $98^{+}$ & $69^{+}$ & From $p$ of $\mathrm{C}_{7} \mathrm{H}_{14}$ cyclopentanes. \\
\hline $50.4 \ldots$ & $100^{+}$ & $71^{+}$ & From $p$ of $n$-heptane. \\
\hline $57.8 \ldots$ & $108^{+}$ & $79^{+}$ & From $p$ of vinylcyclohexene. \\
\hline 61.5 & $112^{+}$ & $83^{+}$ & From $p$ of $\mathrm{C}_{8} \mathrm{H}_{10}$ olefins and eyclics. \\
\hline $63.4 \ldots \ldots$ & $114^{+}$ & $85^{+}$ & From $p$ of $n$-octane and $3,4 \mathrm{me}_{2}$ hexane. \\
\hline 69.0 & $120^{+}$ & $91^{+}$ & From $p$ of propylbenzenes. \\
\hline 74.7 & $126^{+}$ & $97^{+}$ & From $p$ of $n$-butyl cyclopentane. \\
\hline $76.6 \ldots$ & $128^{+}$ & $99^{+}$ & From $p$ of $n$-nonane. \\
\hline $82.3 \ldots$ & $134^{+}$ & $105^{+}$ & From $p$ of $\mathrm{C}_{10} \mathrm{H}_{14}$ alkyl benzenes. \\
\hline $88.0_{-1}$ & $140^{+}$ & $111^{+}$ & $\begin{array}{l}\text { From } p \text { of sec. butyl cyclohexane and } \\
\text { 1-decene. }\end{array}$ \\
\hline $89.9 \ldots \ldots$ & $142^{+}$ & $113^{+}$ & From $p$ of $n$-decane. \\
\hline
\end{tabular}

Loss of mass 30 (table 9). This is another metastable transition that always comes from parent ions. Loss of $\mathrm{C}_{2} \mathrm{H}_{6}$ from a hydrocarbon requires either a double dissociation or a rearrangement of hydrogen atoms in the dissociation process. In most of the $\mathrm{C}_{8} \mathrm{H}_{16}$ isomers that give this and in the last two transitions listed, there is only one $\mathrm{CH}_{3}$ radical in the structure; and in vinylcyclohexene there is no $\mathrm{CH}_{3}$ radical so that rearrangements seem to be involved in these cases.

TABle 9. Transitions involving loss of mass 30

\begin{tabular}{|c|c|c|c|}
\hline$m_{a}$ & $m_{i}$ & $m_{f}$ & Occurrence \\
\hline $24.5 \ldots$ & $72^{+}$ & $42^{+}$ & From $p$ of $n$-pentane. \\
\hline $36.5 \ldots$ & $86^{+}$ & $56^{+}$ & From $p$ of $n$-hexane. \\
\hline $49.0 \ldots$ & $100^{+}$ & $70^{+}$ & From $p$ of heptanes. \\
\hline $56.3 \ldots$ & $108^{+}$ & $78^{+}$ & From $p$ of vinylcyclohexene. \\
\hline $60.0_{\ldots}$ & $112^{+}$ & $82^{+}$ & From $p$ of $\mathrm{C}_{8} \mathrm{H}_{16}$ isomers. \\
\hline $61.9 \ldots$ & $114^{+}$ & $84^{+}$ & From $p$ of octanes. \\
\hline $73.1 \ldots$ & $126^{+}$ & $96^{+}$ & From $p$ of $n$-butyl cyclopentane. \\
\hline $86.4 \ldots$ & $140^{+}$ & $110^{+}$ & From $p$ of sec. butyl cyclohexane. \\
\hline
\end{tabular}

Loss of mass 40 (table 10). There is only one instance of the loss of $\mathrm{C}_{3} \mathrm{H}_{4}$ in a metastable transition. It gives a conspicuous peak, and the initial and final states are abundant ions so the evidence is quite conclusive.
TABLE 10. Transitions involving loss of mass 40

\begin{tabular}{|c|c|c|c|}
\hline$m_{a}$ & $m_{\boldsymbol{i}}$ & $m_{f}$ & Occurrence \\
\cline { 2 - 3 } & \multirow{2}{*}{$97^{+}$} & $57^{+}$ & 2,4,4-me3-2-pentene. \\
\hline
\end{tabular}

Loss of mass 42 (table 11). The loss of $\mathrm{C}_{3} \mathrm{H}_{6}$ is a fairly common type of metastable transition observed in a variety of compounds containing seven or more carbon atoms.

TABLE 11. Transitions involving loss of mass 42

\begin{tabular}{|c|c|c|c|}
\hline$m_{a}$ & $m_{i}$ & $m_{f}$ & Occurrence \\
\hline 21. 7 & $85^{+}$ & $43^{+}$ & Heptanes, octanes and nonanes. \\
\hline 31.2 & $97^{+}$ & $55^{+}$ & Olefins and cyclics above $\mathrm{C}_{7}$. \\
\hline 32.0 & $98^{+}$ & $56^{+}$ & From $p$ of $\mathrm{C}_{7} \mathrm{H}_{14}$ isomers and 1-decene. \\
\hline 32.8 & $99^{+}$ & $57^{+}$ & Octanes and nonanes. \\
\hline 40.3 & 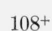 & $66+$ & From $p$ of vinylevclohexene. \\
\hline 43.8 & $112^{+}$ & $70^{+}$ & From $p$ of $\mathrm{C}_{8}$ cyclics. \\
\hline 44.6 & $113^{+}$ & $71^{+}$ & Nonanes. \\
\hline
\end{tabular}

Loss of mass 43 (table 12). There are only three instances in which the propyl radical $\mathrm{C}_{3} \mathrm{H}_{7}$ is lost, and these all involve parent ions.

TABLE 12. Transitions involving loss of mass 43

\begin{tabular}{|c|c|c|c|}
\hline$m_{a}$ & $m_{i}$ & $m_{f}$ & occurrence \\
\hline 54.7 & $126^{+}$ & $83^{+}$ & From $p$ of propylcyclohexanes. \\
\hline 67.2 & $140^{+}$ & $97^{+}$ & From $p$ of $i$-butyleyclohexane. \\
\hline
\end{tabular}

Loss of mass 44 (table 13). Loss of $\mathrm{C}_{3} \mathrm{H}_{8}$, like the loss of $\mathrm{C}_{2} \mathrm{H}_{6}$, requires a double dissociation or a rearrangement of atoms in the dissociation process.

TABLE 13. Transitions involving loss of mass 44

\begin{tabular}{|c|c|c|c|}
\hline$m_{a}$ & $m_{i}$ & $m f$ & Occurrence \\
\hline $31.4 \ldots$ & $100^{+}$ & $56^{+}$ & From $p$ of heptanes. \\
\hline $53.4 \ldots$ & $126^{+}$ & $82^{+}$ & From $p$ of $n$-propylcyclohexane. \\
\hline
\end{tabular}

Loss of masses 56, 57, and 58 (table 14). There are only a few instances of metastable transitions involving the loss of four carbon atoms and all these occur from parent ions of $\mathrm{C}_{10} \mathrm{H}_{20}$ isomers losing $\mathrm{C}_{4} \mathrm{H}_{8}, \mathrm{C}_{4} \mathrm{H}_{9}$, and $\mathrm{C}_{4} \mathrm{H}_{10}$. Loss of a buty] 
radical, $\mathrm{C}_{4} \mathrm{H}_{9}$, from these molecules involves simple breaking of a carbon bond. Loss of $\mathrm{C}_{4} \mathrm{H}_{8}$ or $\mathrm{C}_{4} \mathrm{H}_{10}$ would involve a rearrangement or double dissociation.

TABle 14. Loss of masses 56, 57, and 58

\begin{tabular}{|c|c|c|}
\hline$m_{a}$ & Transition & Occurrence \\
\hline $50.4 \ldots$ & $140^{+} \rightarrow 84^{+}+56$ & From $p$ of 1-decene. \\
\hline $49.2 \ldots$ & $140^{+} \rightarrow 83^{+}+57$ & From $p$ of 1-decene and butylcyclohexanes. \\
\hline $48.0 \ldots$ & $140^{+} \rightarrow 82^{+}+58$ & From $p$ of butylcyclohexanes. \\
\hline
\end{tabular}

\section{Discussion}

The interest in compiling data on occurrence of metastable transitions is that the transitions give some evidence as to the mechanism by which molecule ions dissociate. In the case of dissociations that give normal peaks, the dissociation takes place within the ionization chamber in less than $10^{-7}$ sec. If, however, the half-life for the dissociation transition is of the order of $10^{-6} \mathrm{sec}$, then some of the transitions take place after the ion has traversed the ion accelerating field, and metastable transition peaks are observed. Because of this delay the different kinds of transitions are sorted out and distinguished from each other. If the initial mass is the parent ion, then a single dissociation is involved. If it is not, then there are at least two stages involved in the dissociation process, one within the ionization chamber and one delayed transition. This multiple dissociation occurs more frequently than single dissociation. The above results show that often the metastable transition is not a simple dissociation but involves either a rearrangement of atoms or a multiple dissociation. The following considerations show that a rearrangement involving transfer of one hydrogen atom can explain most of the cases other than simple dissociation.

$\mathrm{By}$ far the most common type of metastable transition is the loss of two hydrogen atoms. It is known from appearance potential measurements that hydrogen atoms are commonly lost from the molecule ion as $\mathrm{H}_{2}$ and not $2 \mathrm{H}$ [6]. This suggests that in all metastable transitions involving loss of mass 2 there is a rearrangement to form $\mathrm{H}_{2}$ in the dissociation process. As the loss of $\mathrm{H}$ in a metastable transition is very rare, it is not attractive to assume that loss of $2 \mathrm{H}$ in two separate processes is common. It seems more probable to assume that the affinity between $\mathrm{H}$ atoms favors removal of pairs of atoms in the form $\mathrm{H}_{2}$.

Appearance potential measurements also give some evidence as to transitions involving loss of $\mathrm{CH}_{4}$ (table 4). Stevenson and Hipple [7] find that in the butanes the transition $58^{+} \rightarrow 42^{+}+16$ gives $\mathrm{CH}_{4}$ and not $\mathrm{CH}_{3}+\mathrm{H}$. This suggests that all metastable transitions involving loss of $\mathrm{CH}_{4}$ involve a similar process. The affinity of the methyl radical for $\mathrm{H}$ removes an additional atom in the dissociation process. Transitions involving loss of mass 30 (table 9), 44 (table 13), and 58 (table 14) probably involve the same mechanism. All except one of these transitions can be explained by transfer of only one $\mathrm{H}$ atom in the dissociation process. Removal of mass 30 from vinylcyclohexene involves more complicated rearrangements.

The losses of $\mathrm{CH}_{3}$ (table 3), $\mathrm{C}_{2} \mathrm{H}_{5}$ (table 8), $\mathrm{C}_{3} \mathrm{H}_{7}$ (table 12), and $\mathrm{C}_{4} \mathrm{H}_{9}$ (table 14) from parent ions can in most cases be ascribed to simple breaking of a carbon bond. Two exceptions are the loss of $\mathrm{CH}_{3}$ from cyclopentane and cyclohexane. The mass spectra of these are much like 1-pentene and 1-hexene, and it seems probable that in the cyclics the ring breaks with a rearrangement of $\mathrm{H}$ atoms to give $\mathrm{CH}_{3}$ at one end and $\mathrm{CH}$ at the other and that the metastable transition follows this. Loss of $\mathrm{CH}_{3}$ from 1,3-butadiene and loss of $\mathrm{C}_{2} \mathrm{H}_{5}$ from vinylcyclohexene also involve rearrangements.

The losses of $\mathrm{C}_{2} \mathrm{H}_{2}$ (table 5), $\mathrm{C}_{2} \mathrm{H}_{4}$ (table 7), and $\mathrm{C}_{3} \mathrm{H}_{6}$ (table 11) can come from simple breaking of a carbon bond in cases where the initial ion is not a parent ion. In cases where it is a parent ion, a rearrangement of hydrogen atoms or a double dissociation is required since breaking one bond in a hydrocarbon gives radicals with an odd number of $\mathrm{H}$ atoms, except in the case of breaking a ring.

Nearly all the observed metastable transitions can be accounted for as single dissociation processes. In this dissociation one additional hydrogen atom may be transferred to either the charged or uncharged fraction of the dissociating ion. This transfer of a hydrogen atom is very common. Only a few of all the observed transitions require more complicated rearrangements, and in these 
cases an isomerization of the initial ion probably precedes the dissociation.

The results show that ions dissociate in a great variety of ways, either in several successive stages or by loss of a rather large fragment in one step, but loss of more than three carbon atoms in one metastable transition is rare and only observed in a few $\mathrm{C}_{10}$ hydrocarbons.

The intensity rule relating height of the metastable peak to the intensity of the initial and final ions is quite general, and there are only a few instances where metastable transitions are distinctive of a given compound when the normal spectra are similar. That the peak at 28.2 (table 3 ) is missing in 1,2-butadiene and present in other $\mathrm{C}_{4} \mathrm{H}_{6}$ isomers has been noted [1]. The discussion of table 4 mentions another distinctive difference found in two $\mathrm{C}_{8}$ cyclohexanes. In general metastable transition peaks are not useful in identification of unknown compounds in a chemical analysis, but it is essential to include them in a careful description of the spectrum.

\section{References}

[1] Evelyn G. Bloom, Fred L. Mohler, J. H. Lengel, and C. Edward Wise, J. Research NBS 40, 437 (1948) RP1888.

[2] American Petroleum Institute Catalog of Mass Spectral Data. Research Project 44, National Bureau of Standards.

[3] J. A. Hipple and E. U. Condon, Phys. Rev. 68, 54 (1945).

[4] API Catalog of Mass Spectral Data, Table No. 120.

[5] K. S. Pitzer and C. W. Beckett, J. Chem. Soc. 69, 977 (1947).

[6] J. A. Hipple, Phys. Rev. 53, 530 (1938).

[7] D. P. Stevenson and J. A. Hipple, J. Am. Chem. Soc. 64, 1588 (1942).

Washington, March 16, 1949. 